\title{
FONTES E DOSES DE MOLIBDÊNIO VIA FOLIAR EM DUAS CULTIVARES DE FEIJOEIRO ${ }^{1}$
}

\author{
MARCELO VIEIRA DA SILVA ${ }^{2}$ \\ MESSIAS JOSÉ BASTOS DE ANDRADE ${ }^{3}$ \\ AUGUSTO RAMALHO DE MORAES ${ }^{4}$ \\ VANDEIR GREGÓRIO ALVES ${ }^{2}$
}

\begin{abstract}
RESUMO - Visando a estudar a resposta de duas cultivares de feijoeiro (Phaseolus vulgaris L.) a fontes e doses de molibdênio via foliar, foram conduzidos três ensaios em um Latossolo Vermelho distroférrico típico (seca e inverno-primavera 97) e um Podzólico Vermelho-Amarelo (águas 97/98) do município de Lavras, Minas Gerais. O delineamento experimental foi de blocos casualizados, com três repetições, em esquema fatorial $2 \times 2 \times 4$ envolvendo duas cultivares (Carioca e Carioca-MG), duas fontes de Mo (molibdatos de sódio e de
\end{abstract} TERMOS PARA INDEXAÇÃO: Adubação foliar, adubação molíbdica, Phaseolus vulgaris.

\section{MOLYBDENUM SOURCES AND RATES APPLIED ON LEAVES OF TWO COMMON BEAN CULTIVARS}

\begin{abstract}
Three field experiments were conducted in southern Minas Gerais State, on distrofic Dusky Red Latosol (1997 summer/fall and winter/spring growing seasons) and on a Red Yellow Podzolic (1997/98 summer season), to study the response of two common bean cultivars (Phaseolus vulgaris L.) to molybdenum (Mo) sources and rates of application on leaves. The experimental design was randomized blocks with three replications and a $2 \times 2 \times 4$ factorial arrangement, involving two bean cultivars (Carioca and CariocaMG), two Mo sources (sodium and ammonium
\end{abstract}

molybdates) and four Mo rates (0, 50, 100, and $150 \mathrm{~g}$ ha ${ }^{1} \mathrm{Mo}$ ), applied on leaves at 21-25 days after emergency . At harvest, the grain yield and their primary components (number of pod per plant, number of grains per pod and weight of one hundred seeds), and the final stand, were evaluated. Results showed no effect of the molybdenum sources on grain yield and yield components. In both cultivars, grain yield increased with increasing Mo rates up to $54 \mathrm{~g} \mathrm{ha}^{-1}$ of Mo, following a discontinuous linear response, or LPR (Linear Response-Plateau).

amônio) e quatro doses do micronutriente $(0,50,100 \mathrm{e}$ ge $\mathrm{Mo}$ ), aplicadas via foliar entre 21 e 25 dias dimento de grãos, os seus componentes primários (número de vagens por planta, número de grãos por vagem e análise conjunta, verificou-se que as fontes de Mo não influenciaram o rendimento de grãos e seus componentes. As doses crescentes de Mo aumentaram linearmente o rendimento de grãos até a dose de $54 \mathrm{~g} \mathrm{ha}^{-1}$ de Mo. após a emergência. Na colheita foram avaliados o renmassa de cem grãos) e o estande final. Pelos resultados da

INDEX TERMS: Foliar fertilization, molybdenum fertilization, Phaseolus vulgaris.

\section{INTRODUÇÃO}

Entre os micronutrientes essenciais, o molibdênio (Mo) tem despertado grande interesse entre pesquisadores e produtores envolvidos com a cultura do feijoeiro, principalmente por causa dos resultados espetacu- lares que vêm sendo obtidos com a adubação molíbdica foliar (Vieira, 1994 a; Rodrigues et al., 1996).

A aplicação foliar de molibdênio eleva os teores de nitrogênio nas folhas dos feijoeiros, que se tornam

1. Parte de projeto financiado pela FAPEMIG.

2. Engenheiro Agrônomo, mestrando, bolsista do CNPq. Departamento de Agricultura (DAG), UNIVERSIDADE FEDERAL DE LAVRAS (UFLA), Caixa Postal 37, 37200-000 - Lavras, MG.

3. Engenheiro Agrônomo, D.Sc., Professor Adjunto, DAG/UFLA, bolsista do CNPq.

4. Engenheiro Agrônomo, DSc., Professor Adjunto, Departamento de Ciências Exatas, UFLA. 
bem mais verdes e, freqüentemente, aumenta o tamanho dos grãos, o número de vagens por planta e, conseqüentemente, o rendimento de grãos (Amane et al., 1994; Alvarenga, 1995; Andrade et al., 1998 b). Existem fortes evidências de que esse efeito positivo esteja relacionado com melhoria na eficiência da assimilação de nitrogênio, seja ele proveniente da atmosfera, via fixação simbiótica (em que o Mo é requerido no sistema enzimático da nitrogenase) ou oriundo da absorção radicular e posterior redução na planta, processo em que o Mo é requerido no sistema enzimático da redutase do nitrato (Vieira, 1994 b; Andrade et al., 1998a).

Em Lavras-MG, a aplicação de doses crescentes de Mo $\left(0,40,80\right.$ e $\left.120 \mathrm{~g} \mathrm{ha}^{-1}\right)$, fonte molibdato de amônio aos 25 dias após emergência, não revelou comportamento diferencial das cultivares Ouro Negro, CariocaMG, Jalo-ESAL, Ouro e Roxo 90, mas mostrou efeito quadrático das doses de Mo sobre o rendimento de grãos, com pontos de máximo entre 76 e $80,7 \mathrm{~g} \mathrm{ha}^{-1} \mathrm{de}$ Mo, dependendo da safra considerada. Houve também efeito quadrático sobre os componentes do rendimento (exceto número de grãos por vagem) e índice de colheita (Rodrigues et al., 1996).

Na região de Viçosa, também em Minas Gerais, Berger et al. (1996) verificaram que a dose de $78 \mathrm{~g}$ $\mathrm{ha}^{-1}$ de Mo proporcionou a maior produtividade de grãos $\left(1682 \mathrm{~kg} \mathrm{ha}^{-1}\right)$ e que a época mais propícia para essa aplicação foi de 14 a 28 dias após a emergência do feijoeiro.

Em seu estudo com três níveis de adubação nitrogenada na semeadura $\left(0,20\right.$ e $40 \mathrm{~kg} \mathrm{ha}^{-1}$ de N), dois níveis de adubação nitrogenada em cobertura (0 e $30 \mathrm{~kg}$ $\mathrm{ha}^{-1}$ de $\left.\mathrm{N}\right)$ e dois níveis de adubação molíbdica foliar (0 e $40 \mathrm{~g} \mathrm{ha}^{-1}$ de Mo fonte molibdato de amônio), Andrade et al. (1998 b) verificaram que, de maneira geral, houve efeito significativo dos três fatores sobre o rendimento de grãos e seus componentes. As interações, entretanto, não foram significativas. A aplicação foliar de molibdênio aumentou significativamente o rendimento de grãos, o número de vagens por planta e a massa de cem sementes, assim como os teores foliares de nitrogênio, cálcio e magnésio. A cultivar empregada foi a Carioca-MG e o aumento da produtividade em razão da aplicação foliar do molibdênio foi de $39 \%\left(976 \mathrm{~kg} \mathrm{ha}^{-1}\right.$ para $1355 \mathrm{~kg}$ ha ${ }^{1}$ ), ou seja, da mesma magnitude que o acréscimo atribuído ao nitrogênio em cobertura $\left(973 \mathrm{~kg} \mathrm{ha}^{-1}\right.$ para 1358 $\left.\mathrm{kg} \mathrm{ha}^{-1}\right)$.

A magnitude da resposta do feijoeiro à aplicação foliar de $40 \mathrm{~g} \mathrm{ha}^{-1}$ de Mo (fonte molibdato de amônio) em relação a diferentes formas de fornecimento de nitrogênio (sem N, N semeadura $+\mathrm{N}$ cobertura, inocula- ção com Rhizobium e inoculação + N cobertura) foi estudada por Alvarenga (1995). Nesse estudo, a interação N x Mo somente foi significativa para as características massa de cem grãos, índice de colheita e matéria seca de flores + vagens. O molibdênio proporcionou a obtenção de plantas mais altas e com maior número de vagens, resultando em acréscimo de produtividade da ordem de $91 \%$ em relação à testemunha sem $\mathrm{N}$ e sem Mo (2103 $\mathrm{kg} \mathrm{ha}^{-1}$ contra $1100 \mathrm{~kg} \mathrm{ha}^{-1}$ ); esse efeito foi superior ao tratamento inoculação + nitrogênio em cobertura (acréscimo da ordem de 48\%) e comparável ao acréscimo propiciado pelo tratamento $\mathrm{N}$ semeadura $+\mathrm{N}$ cobertura (acréscimo da ordem de $93 \%$ ).

Analisando-se resultados mais recentes, verificase ainda que em solos muito pobres em Mo a dose ideal do micronutriente pode depender das doses de $\mathrm{N}$ no plantio ou cobertura (Araújo et al., 1999), e que a mistura da fonte molíbdica com defensivos na mesma cauda não apresenta problemas (Silva et al., 1999).

Apesar de serem conhecidos esses resultados, todos eles foram obtidos com o molibdato de amônio, não sendo conhecido o comportamento de outras fontes de Mo quando aplicadas sobre a cultura do feijoeiro. Assim, com o presente trabalho objetivou-se estudar a resposta de duas cultivares de feijoeiro (Phaseolus vulgaris L.) à aplicação de diferentes doses de Mo via foliar, com o emprego de distintas fontes desse micronutriente.

\section{MATERIAL E MÉTODOS}

Foram conduzidos três ensaios de campo em área experimental do Departamento de Agricultura da Universidade Federal de Lavras (UFLA), Lavras-MG, em solos classificados como Latossolo Vermelho distroférrico típico (seca e inverno 97) e Podzólico VermelhoAmarelo (águas 97/98) e cujos resultados da análise química encontram-se na Tabela 1. Em todos eles, o preparo do solo constou de uma aração e duas gradagens leves.

Por ocasião da semeadura, utilizou-se o fertilizante formulado 4-14-8, na base de $600 \mathrm{~kg} \mathrm{ha}^{-1}$, o qual foi distribuído e misturado com o solo no fundo do sulco. Foi ainda aplicado nos sulcos o inseticida sistêmico forate (Granutox, $15 \mathrm{~kg} \mathrm{ha}^{-1}$ p.c.), visando ao controle de pragas iniciais da cultura. Adotou-se o espaçamento de $0,5 \mathrm{~m}$ entre linhas, profundidade de $5 \mathrm{~cm}$ e densidade 16 sementes por metro.

O delineamento experimental foi de blocos casualisados, com três repetições, em esquema fatorial 
$2 \times 2 \times 4$ envolvendo duas cultivares (Carioca e CariocaMG), duas fontes de Mo (molibdatos de sódio e de amônio) e quatro doses de Mo $\left(0,50,100\right.$ e $150 \mathrm{~g} \mathrm{ha}^{-1} \mathrm{de}$ Mo) aplicadas via foliar.

Foram utilizadas parcelas de $10 \mathrm{~m}^{2}(2,0 \mathrm{~m} \times 5,0$ $\mathrm{m})$, com área útil de $5,0 \mathrm{~m}^{2}$, o que correspondeu às duas linhas centrais.

As aplicações de molibdênio nos experimentos da seca, inverno-primavera e águas ocorreram, respectivamente, aos 21,24 e 20 dias após emergência e foram realizadas com pulverizador à pressão constante de $\mathrm{CO}_{2}\left(45 \mathrm{lb} \mathrm{pol}^{-2}\right)$, para maior precisão das dosagens, e vazão de $300 \mathrm{~L} \mathrm{ha}^{-1}$, adicionando-se $1 \%\left(\mathrm{v} \mathrm{v}^{-1}\right)$ de espalhante adesivo Agral. As fontes, molibdatos de sódio e de amônio foram utilizadas na forma de reagentes puros para análise (p.a.).

Por ocasião da colheita, foram avaliados o estande final, o rendimento de grãos e os componentes do rendimento (número de vagens por planta, número de grãos por vagem e massa de cem grãos). $\mathrm{O}$ estande final foi obtido pela contagem do número total de plantas. Os grãos provenientes da debulha de todas as vagens forneceu, por pesagem, o rendimento de grãos. O número médio de vagens por planta e o número médio de grãos por vagem foram determinados em amostra aleatória de dez plantas e a massa de cem grãos, pela média de três pesagens de cem grãos tomados ao acaso.

Todos os dados foram submetidos à análise de variância individual por ensaio e conjunta. Tanto isoladamente quanto nas interações, os efeitos de safra, cultivar ou fonte de molibdênio foram estudados por meio de comparação de médias pelo teste Tukey, e os efeitos de doses, estudados por meio de análise de regressão (Gomes, 1990).

TABELA 1 - Resultados de análises químicas dos solos utilizados nos experimentos. UFLA, Lavras, MG, $1996 / 98^{1}$.

\begin{tabular}{lccr}
\hline \multirow{2}{*}{ Característica } & \multicolumn{3}{c}{ Safra } \\
\cline { 2 - 4 } & \multicolumn{1}{c}{ Seca 97 } & Inverno 97 & Águas 97/98 \\
\hline $\mathrm{pH} \mathrm{em} \mathrm{H} \mathrm{H}_{2} 0(1: 2,5)$ & $6,0 \mathrm{AcF}$ & $5,5 \mathrm{AcM}$ & $4,6 \mathrm{AcE}$ \\
$\mathrm{P}\left(\mathrm{mg} \mathrm{dm}^{-3}\right)$ & $7 \mathrm{Ba}$ & $6 \mathrm{Ba}$ & $9 \mathrm{M}$ \\
$\mathrm{K}\left(\mathrm{mg} \mathrm{dm}^{-3}\right)$ & $67 \mathrm{M}$ & $31 \mathrm{Ba}$ & $55 \mathrm{M}$ \\
$\mathrm{Ca} \mathrm{trocável}\left(\mathrm{cmol}_{\mathrm{c}} \mathrm{dm}^{-3}\right)$ & $3,4 \mathrm{Bo}$ & $2,6 \mathrm{Bo}$ & $1,3 \mathrm{M}$ \\
$\mathrm{Mg}$ trocável $\left(\mathrm{cmol}_{\mathrm{c}} \mathrm{dm}^{-3}\right)$ & $1,5 \mathrm{Bo}$ & $1,2 \mathrm{Bo}$ & $0,6 \mathrm{M}$ \\
$\mathrm{Al} \mathrm{trocável}\left(\mathrm{cmol}_{\mathrm{c}} \mathrm{dm}^{-3}\right)$ & $0,0 \mathrm{MBa}$ & $0,0 \mathrm{MBa}$ & $0,6 \mathrm{M}$ \\
$\mathrm{H}+\mathrm{Al}_{\left(\mathrm{cmol}_{\mathrm{c}} \mathrm{dm}^{-3}\right)}$ & $2,3 \mathrm{Ba}$ & $4,5 \mathrm{M}$ & $6,3 \mathrm{Bo}$ \\
$\mathrm{S}\left(\mathrm{cmol}_{\mathrm{c}} \mathrm{dm}^{-3}\right)$ & $5,1 \mathrm{Bo}$ & $3,9 \mathrm{Bo}$ & $2,0 \mathrm{M}$ \\
$\mathrm{t}\left(\mathrm{cmol}_{\mathrm{c}} \mathrm{dm}^{-3}\right)$ & $5,1 \mathrm{Bo}$ & $3,9 \mathrm{M}$ & $2,6 \mathrm{M}$ \\
$\mathrm{T}\left(\mathrm{cmol}_{\mathrm{c}} \mathrm{dm}^{-3}\right)$ & $7,4 \mathrm{M}$ & $8,4 \mathrm{M}$ & $8,3 \mathrm{M}$ \\
$\mathrm{m}(\%)$ & $0 \mathrm{MBa}$ & $0 \mathrm{MBa}$ & $23 \mathrm{~B}$ \\
$\mathrm{~V}(\%)$ & $69 \mathrm{Bo}$ & $46 \mathrm{M}$ & $24 \mathrm{Ba}$ \\
\hline $\mathrm{A}(\%$ áls rea
\end{tabular}

Análises realizadas pelos Laboratórios do Departamento de Ciências do Solo da UFLA e interpretação de acordo com Ribeiro et al.. (1999). AcM= acidez média, AcF=acidez fraca, $A c E=$ acidez elevada, Bo=teor bom, $\mathrm{M}=$ teor médio, $\mathrm{Ba}=$ teor baixo, Mba=teor muito baixo. 


\section{RESULTADOS E DISCUSSÃO}

A análise de variância conjunta dos três ensaios revelou que foi boa a precisão experimental, já que os valores do coeficiente de variação (Tabela 2) mostraram-se próximos dos normalmente obtidos com o feijoeiro em Minas Gerais (Abreu et al., 1994). Detectou-se efeito significativo de safras e de cultivares sobre todas as variáveis estudadas, bem como da interação safras x cultivares sobre o rendimento de grãos, número de vagens por planta, massa de cem grãos e estande final. As diferentes doses de molibdênio afetaram significativamente o rendimento e o número de vagens, enquanto o estande mostrou-se significativamente influenciado pela interação safra $\mathrm{x}$ cultivar $\mathrm{x}$ fonte.
Os valores médios das características avaliadas nos três ensaios são apresentados nas Tabelas 2,3 e 4 . De maneira geral, as safras de inverno-primavera e seca apresentaram maiores rendimentos médios de grãos que o das águas. O comportamento das cultivares foi diferenciado nas diferentes épocas de semeadura, pois não diferiram na seca, mas a 'Carioca-MG' produziu mais no inverno $(+31 \%)$ e nas águas $(+89 \%)$. Verificou-se ainda que o maior rendimento da cv. Carioca-MG pode ter resultado de maiores valores dos três componentes do rendimento (Tabelas 2 e 3), e que o seu menor estande final (Tabela 4) não foi suficiente para mascarar a sua superioridade, o que provavelmente está ligado ao seu crescimento indeterminado, dotado de maior plasticidade ou capacidade de compensação (Nienhuis \& Singh, 1985).

TABELA 2 - Valores médios do rendimento de grãos e número de vagens por planta. UFLA, Lavras-MG, $1997 / 98^{1}$.

\begin{tabular}{|c|c|c|c|c|c|c|c|c|}
\hline \multirow{2}{*}{ Fator } & \multicolumn{4}{|c|}{ Rendimento (kg /ha) } & \multicolumn{4}{|c|}{ Número de Vagens por Planta } \\
\hline & Seca & Inverno & Águas & Média & Seca & Inverno & Águas & Média \\
\hline \multicolumn{9}{|l|}{ Cultivar: } \\
\hline Carioca & 1983 a A & $1756 \mathrm{~b} \mathrm{~A}$ & 689 b B & $1476 \mathrm{~b}$ & $9,85 \mathrm{~b} \mathrm{~A}$ & 9,04 a $\mathrm{A}$ & 5,58 b B & $8,16 \mathrm{~b}$ \\
\hline Carioca-MG & 1903 a B & 2293 a A & 1305 a C & 1834 a & 15,01 a $\mathrm{A}$ & 8,98 a B & 7,57 a B & 10,52 a \\
\hline \multicolumn{9}{|l|}{ Fonte: } \\
\hline Mol. Na & 1837 & 2108 & 1032 & 1659 & 12,25 & 8,74 & 6,68 & 9,22 \\
\hline Mol. $\mathrm{NH}_{4}$ & 2049 & 1941 & 962 & 1651 & 12,61 & 9,28 & 6,47 & 9,45 \\
\hline \multicolumn{9}{|l|}{ Dose de Mo: } \\
\hline $0 \mathrm{~g} \mathrm{ha}^{-1}$ & 1879 & 1694 & 719 & 1431 & 12,08 & 7,53 & 4,86 & 8,16 \\
\hline $50 \mathrm{~g} \mathrm{ha}^{-1}$ & 1924 & 2140 & 1077 & 1714 & 12,23 & 9,62 & 6,88 & 9,58 \\
\hline $100 \mathrm{~g} \mathrm{ha}^{-1}$ & 1916 & 2047 & 1046 & 1670 & 13,25 & 8,89 & 7,09 & 9,74 \\
\hline $150 \mathrm{~g} \mathrm{ha}^{-1}$ & 2052 & 2216 & 1145 & 1804 & 12,16 & 10,01 & 7,48 & 9,88 \\
\hline Média & 1943 A & $2024 \mathrm{~A}$ & 997 B & 1655 & $12,43 \mathrm{~A}$ & $9,01 \mathrm{~B}$ & $6,58 \mathrm{C}$ & 9,34 \\
\hline C.V. (\%) & - & - & - & 20,10 & - & - & - & 24,31 \\
\hline
\end{tabular}

* Dentro de cada fator, médias seguidas da mesma letra minúscula nas colunas e maiúscula nas linhas, não diferem significativamente pelo teste de Tukey ao nível de $5 \%$ de probabilidade. 
Observa-se que o rendimento de grãos e seus componentes pouco diferiram em relação às duas fontes de molibdênio utilizadas, inferindo-se que molibdato de sódio e molibdato de amônio podem ser utilizados indistintamente (Tabelas 2 e 3). Pode-se verificar ainda, na Tabela 4, que à exceção do baixo estande na época da seca, não houve maiores diferenças em função das fontes e demais safras. Como não houve significância na análise de regressão do estande em função de doses, acredita-se que o baixo estande citado possa ter sido responsável, pelo menos parcialmente, pela significância da interação época $\mathrm{x}$ cultivar $\mathrm{x}$ fonte.

TABELA 3 - Valores médios do número de grãos por vagem e massa de cem grãos. UFLA, Lavras, MG, 1997/98*.

\begin{tabular}{|c|c|c|c|c|c|c|c|c|}
\hline \multirow{2}{*}{ Fator } & \multicolumn{4}{|c|}{ Número de Grãos por Vagem } & \multicolumn{4}{|c|}{ Massa de 100 Grãos (g) } \\
\hline & Seca & Inverno & Águas & Média & Seca & Inverno & Águas & Média \\
\hline \multicolumn{9}{|l|}{ Cultivar: } \\
\hline Carioca & 4,92 & 4,63 & 3,58 & $4,38 \mathrm{~b}$ & 18,64 a $\mathrm{A}$ & 19,00 a $\mathrm{A}$ & 16,06 b B & $17,90 \mathrm{~b}$ \\
\hline Carioca-MG & 5,60 & 5,23 & 3,88 & $4,90 \mathrm{a}$ & 18,16 a B & 19,11 a $\mathrm{A}$ & 18,49 а $\mathrm{AB}$ & 18,59 a \\
\hline \multicolumn{9}{|l|}{ Fonte: } \\
\hline Mol. Na & 5,24 & 4,91 & 3,85 & 4,67 & 18,35 & 19,11 & 17,39 & 18,29 \\
\hline Mol. $\mathrm{NH}_{4}$ & 5,28 & 4,95 & 3,61 & 4,61 & 18,45 & 19,00 & 17,16 & 18,20 \\
\hline \multicolumn{9}{|l|}{ Dose de Mo: } \\
\hline $0 \mathrm{~g} \mathrm{ha}^{-1}$ & 5,26 & 4,97 & 3,65 & 4,63 & 18,73 & 18,66 & 17,11 & 18,17 \\
\hline $50 \mathrm{~g} \mathrm{ha}^{-1}$ & 5,28 & 4,95 & 3,67 & 4,63 & 18,25 & 19,16 & 17,08 & 18,16 \\
\hline $100 \mathrm{~g} \mathrm{ha}^{-1}$ & 5,23 & 4,81 & 3,61 & 4,55 & 18,42 & 18,95 & 17,17 & 18,18 \\
\hline $150 \mathrm{~g} \mathrm{ha}^{-1}$ & 5,28 & 5,00 & 4,00 & 4,76 & 18,21 & 19,46 & 17,75 & 18,47 \\
\hline Média & $\begin{array}{l}5,26 \\
\text { A }\end{array}$ & $4,93 \mathrm{~B}$ & $3,73 \mathrm{C}$ & 4,64 & $18,40 \mathrm{~B}$ & $19,06 \mathrm{~A}$ & $17,28 \mathrm{C}$ & 18,25 \\
\hline C.V. (\%) & - & - & - & 10,21 & - & - & - & 5,25 \\
\hline
\end{tabular}

* Dentro de cada fator, médias seguidas da mesma letra minúscula nas colunas e maiúscula nas linhas, não diferem significativamente pelo teste de Tukey ao nível de $5 \%$ de probabilidade.

TABELA 4 - Valores médios do estande final (mil plantas ha ${ }^{-1}$ ) do feijoeiro em função das safras, cultivares e fontes de molibdênio via foliar. UFLA, Lavras-MG, 1997/98*.

\begin{tabular}{|c|c|c|c|c|c|c|c|}
\hline \multirow[b]{2}{*}{ Época } & \multicolumn{3}{|c|}{ Carioca } & \multicolumn{3}{|c|}{ Carioca-MG } & \multirow[t]{2}{*}{ Média } \\
\hline & $\begin{array}{c}\text { Molib. } \\
\text { Sódio }\end{array}$ & $\begin{array}{c}\text { Molib. A- } \\
\text { mônio }\end{array}$ & Média & $\begin{array}{l}\text { Molib. } \\
\text { Sódio }\end{array}$ & $\begin{array}{l}\text { Molib. A- } \\
\text { mônio }\end{array}$ & Média & \\
\hline Seca & $240 \mathrm{~b} \mathrm{~A}$ & $250 \mathrm{~b} \mathrm{~A}$ & $245 \mathrm{~b}$ & $115 \mathrm{c} \mathrm{A}$ & $117 \mathrm{~b} \mathrm{~A}$ & $116 \mathrm{~b}$ & $180 \mathrm{~b}$ \\
\hline Inver. & 276 a A & 286 a A & $281 \mathrm{a}$ & 291 a A & 281 a A & 286 a & $283 \mathrm{a}$ \\
\hline Águas & 276 a A & 275 a A & $276 \mathrm{a}$ & $270 \mathrm{~b} \mathrm{~B}$ & 286 a A & $278 \mathrm{a}$ & $277 \mathrm{a}$ \\
\hline Média & $264 \mathrm{~A}$ & $270 \mathrm{~A}$ & 267 & $225 \mathrm{~A}$ & $228 \mathrm{~A}$ & 226 & 247 \\
\hline C.V. (\%) & - & - & - & - & - & - & 6,38 \\
\hline
\end{tabular}

* Dentro de cada fator, médias seguidas da mesma letra minúscula nas colunas e maiúscula nas linhas, não diferem significativamente pelo teste de Tukey ao nível de $5 \%$ de probabilidade. 
Nas Figuras 1 e 2 estão ilustrados os efeitos das doses de Mo sobre o rendimento de grãos e sobre o número de vagens por planta. Verifica-se que, em ambos os casos, o aumento da dose até valores próximos de 50 $\mathrm{g} \mathrm{ha}^{-1}$ de Mo elevou linearmente aquelas variáveis, as quais, a partir destas doses, alcançaram um patamar que representou acréscimos da ordem de $20 \%$ no rendimento e no número de vagens em relação à dose zero. Esse comportamento caracteriza, segundo Alvarez V. (1985), uma resposta do tipo LRP (Linear Response-Plateau), a qual tem definidos dois segmentos: a um deles se ajusta uma regressão linear, ao passo que o outro é representado pela média da variável dependente (Figuras 1 e 2). Esse modelo, também chamado de "linear descontínuo", apresentou ajuste bem superior $\left(\mathrm{R}^{2}=0.99\right)$ ao do modelo linear simples (valores do $\mathrm{R}^{2}$ entre 0.75 e 0.76 ). Do mesmo modo, o modelo quadrático, além de pior ajuste, levou a doses ótimas de Mo próximas de $150 \mathrm{~g} \mathrm{ha}^{-1}$, fato ainda não registrado com o micronutriente em feijão.
Adotando-se o modelo LRP, portanto, pode-se inferir que o rendimento de grãos aumentou com o incremento da dose de Mo até a dose de $54 \mathrm{~g} \mathrm{ha}^{-1}$ de Mo, estabilizando-se com o emprego de doses maiores. Os presentes resultados divergem dos encontrados por Rodrigues et al. (1996), os quais, trabalhando com doses de até $120 \mathrm{~g} \mathrm{ha}^{-1}$ de Mo, obtiveram efeito quadrático com bom ajuste $\left(\mathrm{R}^{2}=0.99\right)$ e com ponto de máximo entre 70 e $80 \mathrm{~g} \mathrm{ha}^{-1}$ de Mo. Nota-se que no presente ensaio os efeitos máximos foram alcançados com $54 \mathrm{~g} \mathrm{ha}^{-1} \mathrm{de}$ Mo. É provável que essas diferenças de resultados sejam devidas a distintas condições climáticas e edáficas, como as devidas à inclusão, neste presente estudo, de um solo com situação extrema de acidez ( $\mathrm{pH}=4.6$ na época das águas), condição que aumenta a probabilidade de resposta à adição de Mo (Jones, 1957; Catani et al., 1970; Siqueira, 1976; Siqueira \& Veloso, 1978; Santos, 1991; Rodrigues et al., 1996). Sem dúvida, outros fatores climáticos também podem interferir nos resultados, tais como os teores de fósforo, cálcio, $\mathrm{H}+\mathrm{Al}$ e os valores da saturação de bases.

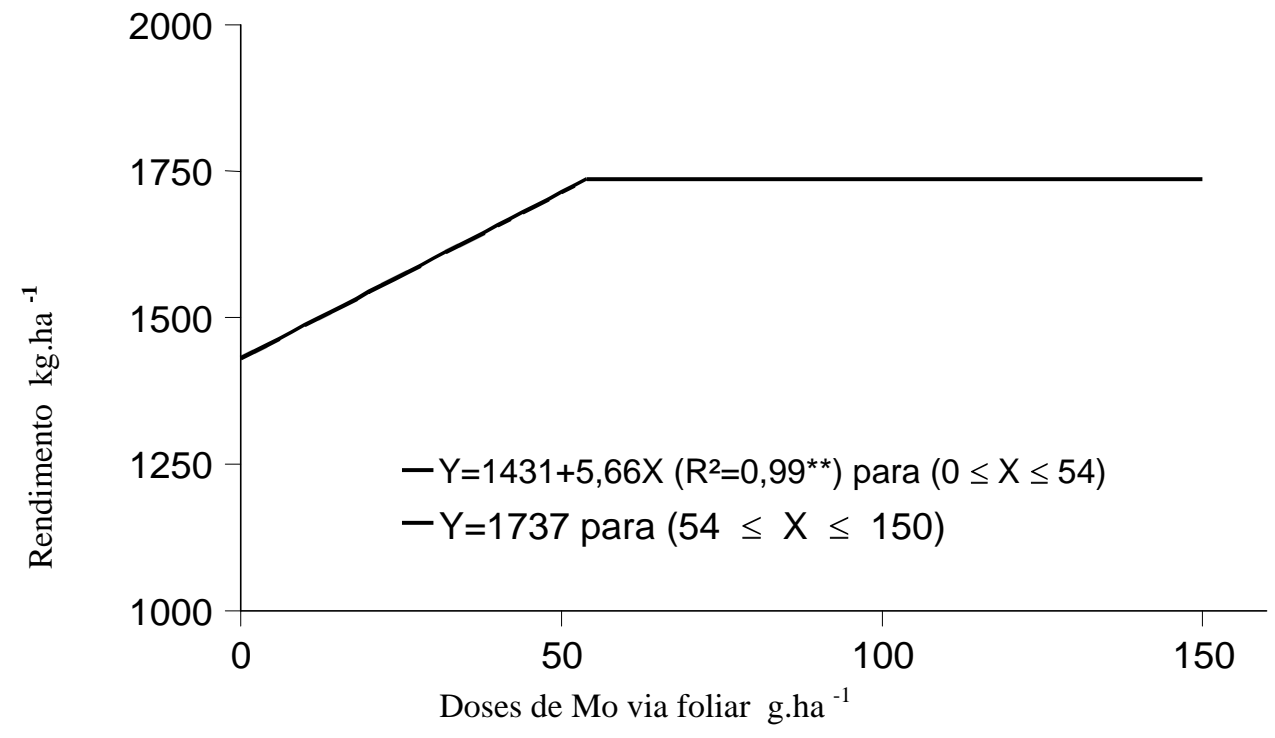

FIGURA 1 - Rendimento de grãos do feijoeiro em função de doses de Mo aplicadas via foliar. UFLA, Lavras, MG, 1997/98. 


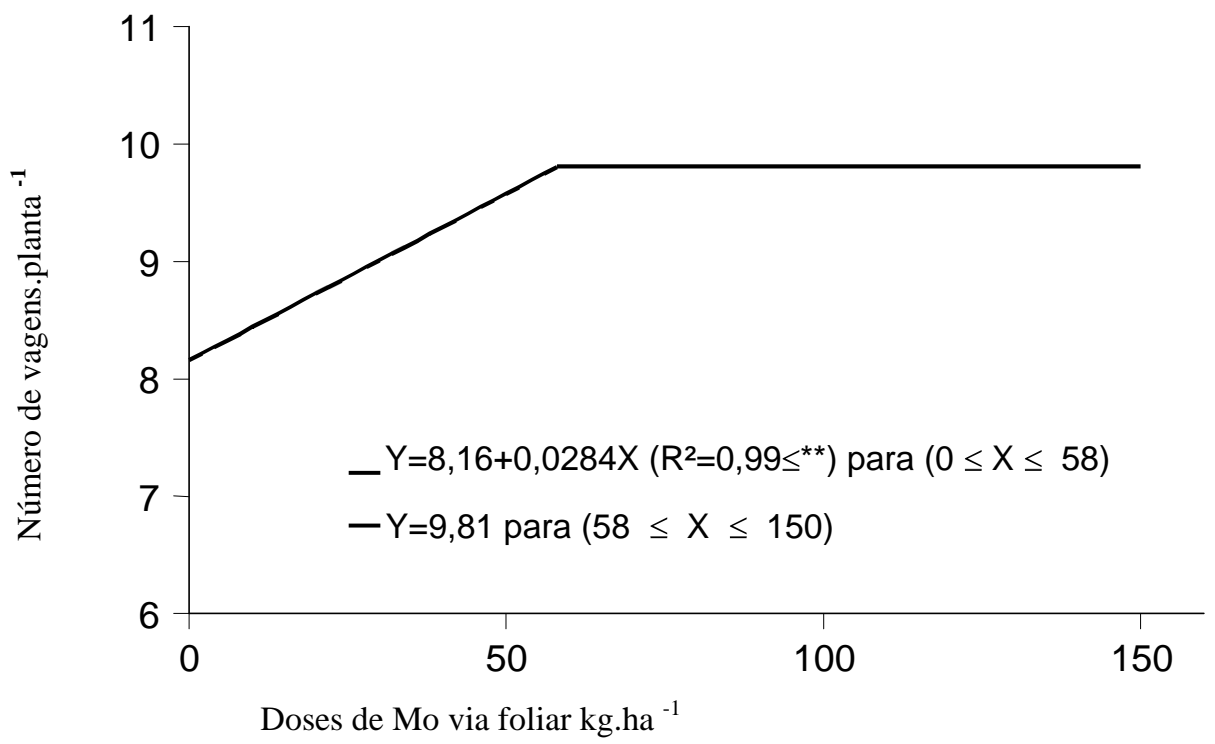

FIGURA 2 - Número de vagens por planta em função de doses de Mo aplicadas via foliar. UFLA, Lavras, MG, 1997/98.

\section{CONCLUSÕES}

a) Molibdato de sódio ou molibdato de amônio podem ser indiferentemente utilizados como fonte de Mo para aplicação foliar no feijoeiro.

b) Em ambas as cultivares, Carioca e CariocaMG, o incremento da dose de Mo elevou o rendimento de grãos de acordo com um modelo linear descontínuo, cujo platô de máximo rendimento foi alcançado com 54 $\mathrm{g} \mathrm{ha}^{-1}$ de Mo.

\section{REFERÊNCIAS BIBLIOGRÁFICAS}

ABREU, A. de F. B.; RAMALHO, M. A. P.; SANTOS, J. B.; MARTINS, L. A. Progresso do melhoramento genético do feijoeiro nas décadas de setenta e oitenta nas regiões Sul e Alto Paranaíba em Minas Gerais. Pesquisa Agropecuária Brasileira, Brasília, v. 29, n. 1, p. 105-112, jan. 1994.

ALVARENGA, P. E. de. Resposta do feijoeiro (Phaseolus vulgaris $\mathrm{L}_{\text {.) }}$ às adubações nitrogenada e molíbdica e à inoculação com Rhizobium leguminosarum bv. phaseoli. 1995. 67 p. Dissertação (Mestrado em Fitotecnia) - Universidade Federal de Lavras, Lavras.

ALVAREZ V., V. H. Avaliação da fertilidade do solo: superfícies de resposta - modelos aproximativos para expressar a relação fator-resposta. Lavras: UFLA, 1985. n. 228, 75 p.
ANDRADE, M. J. B. de; ALVARENGA, P. E.; CARVALHO, J. G. de; SILVA, R. da; NAVES, R. de L. Influência do nitrogênio, rizóbio e molibdênio sobre o crescimento, nodulação radicular e teores de nutrientes no feijoeiro. Revista Ceres, Viçosa, v. 45, n. 257, p. 65-79, 1998a.

ANDRADE, M. J. B. de; DINIZ, A. C.; CARVALHO, J. G. de; LIMA, S. F. de. Resposta da cultura do feijoeiro à aplicação foliar de molibdênio e às adubações nitrogenadas de plantio e cobertura. Ciência e Agrotecnologia, Lavras, v. 22, n. 4, p. 499-508, out./dez., 1998 b.

AMANE, M. I. V.; VIEIRA, C.; CARDOSO, A. A.; ARAÚJO, G. A. de A. Resposta de cultivares de feijão às adubações nitrogenada e molíbdica. Revista Ceres, Viçosa, v. 41, n. 234, p. 202-216. 1994.

ARAÚJO, P. R. A.; ARAÚJO, G. A. de A.; VIEIRA, C.; CARDOSO, A. A. Adubação nitrogenada e molíbdica da cultura do feijão cv. Meia Noite. In: REUNIÃO NACIONAL DE PESQUISA DE FEIJÃO, 6., 1999, Salvador. Anais... Goiânia: EMBRAPA, 1999. p. 735.

BERGER, P. G.; VIEIRA, C.; ARAÚJO, G. A. A. T. A. Efeitos de doses e épocas de aplicação do molibdênio sobre a cultura do feijão. Pesquisa Agropecuária Brasileira, Brasília, v. 31, p. 473-480, 1996. 
CATANI, R. A.; ALCARDE, J. C.; FURLANI, P. R. Adsorção de molibdênio pelo solo. Anais da Escola Superior de Agricultura "Luiz de Queiroz", Piracicaba, v. 27, p. 223-227, 1970.

GOMES, F. P. Curso de estatística experimental. Piracicaba: Escola Superior de Agricultura "Luiz de Queiroz", 1990. 460 p.

JONES, L. H. P. The solubility of molybdenium in simplified sytems and aqueous suspensions. Journal of Soil Science, Edinburgh, v. 8, n. 2, p. 313-327, 1957.

NIENHUIS, J.; SINGH, S. P. Effects of location and plant density on yield and architeetural, traits in dry beans. Crop Science, Madison, v. 25, n. 4, p. 579-584, 1985.

RIBEIRO, A. C.; GUIMARÃES, P. T. G.; ALVAREZ V. V. H. (Ed.). Recomendação para o uso de corretivos e fertilizantes em Minas Gerais - $5^{\text {a }}$ aproximação. Viçosa: Comissão de Fertilidade do Solo do Estado de Minas Gerais, 1999. 359 p.

RODRIGUES, J. R. M.; ANDRADE, M. J. B.; CARVALHO, J. G. Resposta de cultivares de feijão (Phaseolus vulgaris L.) a doses de molibdênio aplicadas via foliar. Ciência e Agrotecnologia, Lavras, v. 20, n. 3, p. 323-333, jul./set. 1996.

SANTOS, O. S. Molibdênio. In: FERREIRA, M. E.; CRUZ, M. C. P. da. Micronutrientes na agricultura. Piracicaba: POTAFOS, 1991. p. 191-217.
SILVA, M. V.; ALVES, V. G.; ANDRADE, M. J. B. de. Aplicação foliar simultânea de molibdênio e defensivos agrícolas na cultura do feijoeiro. In: REUNIÃO NACIONAL DE PESQUISA DE FEIJÃO, 6., 1999 , Salvador. Anais... Goiânia: EMBRAPA, 1999. p. 753.

SIQUEIRA, C. Absorção de molibdato em latosolos sob vegetação de cerrado. 1976.86 p. Dissertação (Mestrado em Ciência do Solo) - Universidade Federal Rural do Rio de Janeiro, Rio de Janeiro.

SIQUEIRA, C.; VELOSO, A. C. Adsorção de molibdênio em solos sob vegetação de cerrado. Revista Brasileira de Ciência do Solo, Campinas, v. 2, p. 24-28, 1978.

VIEIRA, C. Micronutrientes na cultura do feijão. Informe Agropecuário, Belo Horizonte, v. 17, n. 18, p. 4-8, 1994 a.

VIEIRA, R. F. Aplicação foliar de molibdênio e seu efeito nas atividades da nitrogenase e redutase do nitrato no feijoeiro em campo. 1994 b. 188 p. Tese (Doutorado em Solos e Nutrição de Plantas) Escola Superior de Agricultura "Luiz de Queiróz", Piracicaba. 